\title{
A comparison of the effects of soya-bean protein and casein on bile composition, cholelithiasis and serum lipoprotein lipids in the vervet monkey (Cercopithecus aethiops)
}

\author{
BY K. JASKIEWICZ, M. J. WEIGHT, K. J. CHRISTOPHER, A. J. S. \\ BENADÉ, AND D. KRITCHEVSK Y* \\ Research Institute for Nutritional Diseases of the South African Medical Research \\ Council, PO Box 70, Tygerberg 7505, South Africa
}

(Received 5 August 1986-Accepted 27 March 1987)

1. Two groups of vervet monkeys (Cercopithecus aethiops) were fed on high-cholesterol diets which differed only with respect to the protein source. In one group casein was the only protein source, while the other group received only soya-bean protein.

2. Samples of blood, bile and liver biopsy material were collected at the commencement of the study and at 3monthly intervals until termination 12 months later.

3. At the end of the experimental period all the animals ( $n$ 19) had high plasma cholesterol levels and had developed pigment gallstones, the compositions and weights of which were not related to the protein source or to plasma cholesterol levels. Gallstone weight was related to the presence of acidic and sulphated mucins in gallbladder mucosa. We were also unable to confirm the hypocholesterolaemic effect of soya-bean protein which has been demonstrated previously in rhesus monkeys and hamsters. Bile composition and plasma lipids did not differ significantly between the casein-fed and soya-bean fed animals. Lithogenic index was below 1 for both groups and did not differ significantly between the two groups.

4. No significant difference was found in the severity of cholelithiasis between the casein-fed and the soya-beanfed animals.

Cholelithiasis is a common disease in the Western world and is becoming more frequent in developing countries. Set against the high incidence of cholesterol gallstones in Northern Europe and in North and South America, the situation in Japan has been shifting from gallstones composed mainly of pigment, which are becoming less frequent, to those composed largely of cholesterol, becoming more frequent probably in response to the adoption of a high-fat diet (Bennion \& Grundy, 1978). In rural localities in Japan the proportion of patients with pigment lithiasis approaches 70\% (Yagi, 1960; Kameda, 1964). Pigment-store formation has recently also been reported to be a significant factor in the USA, representing $27 \%$ rather than the previously reported $10 \%$ of gallstones found in the general population (Soloway et al. 1977).

The factors leading to cholesterol gallstone formation are probably multiple. Bile supersaturated with cholesterol is a prerequisite for cholesterol cholelithiasis but an increase of lithogenicity can depend on various pathophysiological factors (La Morte et al. 1981). Dietary factors have been identified as being of importance in leading to increased secretion of cholesterol in bile, in obese and particularly in female subjects. Apart from cholesterol, animal fat, carbohydrate and excessive energy intake have also been implicated experimentally in gallstone formation (Sullivan et al. 1985).

In the last few years emphasis has been placed on the effects of dietary proteins on cholelithiasis. Kritchevsky \& Klurfeld $(1979,1983)$ have found in hamsters that soya-bean protein is less cholelithogenic than casein. Sullivan et al. (1985) confirmed that gallstone incidence was greater among hamsters fed on animal protein, but there were no significant differences between experimental groups for serum cholesterol concentrations. Soya-bean

* Present address: The Wistar Institute, Thirty-Sixth Street at Spruce, Philadelphia, PA 19104, USA. 
Table 1. Composition of the experimental diets $(\mathrm{g} / \mathrm{kg})$

\begin{tabular}{lr}
\hline Casein or soya-bean protein & 200 \\
Sucrose & 380 \\
Butter & 200 \\
Maize Oil & 10 \\
Cholesterol & 5 \\
Maize meal +half an apple & 185 \\
Vitamin mix & 10 \\
Mineral mix & 10
\end{tabular} PVM standard mix*

* Dreyer \& Du Bruyn (1968).

protein has also been observed to have a hypocholesterolaemic effect not seen with casein in studies carried out in rhesus monkeys (Terpstra et al. 1984).

The object of the present study was to determine the effects of dietary animal (casein) and vegetable (soya bean) proteins on cholelithiasis, serum lipids, and bile acid composition in vervet monkeys (Cercopithecus aethiops). The study was also considered to be important because the role of diet in the formation of pigment stones is unknown (Soloway, 1977).

\section{MATERIAL AND METHODS}

\section{Animals}

Ten mature male and ten female vervet monkeys, weighing about $5.5 \mathrm{~kg}$ for males and $3.2 \mathrm{~kg}$ for females, were divided into two equal treatment groups of five animals of each sex. Table 1 shows the compositions of the diets they were fed on ad lib. The protein was either casein or soya-bean protein. The monkeys were caged individually in a controlled environment at 24 (SE 0.34$)^{\circ}$ and $50 \%$ humidity with fifteen to twenty air changes per $\mathrm{h}$ and $12 \mathrm{~h}$ artificial lighting cycles. The animals were immobilized at the commencement and regularly at 3-monthly intervals with ketamine hydrochloride (Ketalar; Parke-Davis) for weighing and the taking of blood samples. The liver biopsies and gallbladder bile samples were collected by laparotomy under halothane general anaesthesia.

Monkeys were maintained on experimental diets for 12 months and were fasted for $12 \mathrm{~h}$ before killing. The males were killed by exsanguination under ketamine anaesthesia, the females being preserved for further studies after laparotomy. Gallbladders were removed, and the contents placed in centrifuge tubes and weighed. The bile minus stones, which was separated on standing, was kept for analysis. The gallstones were washed four times in distilled water, dried at $80^{\circ}$ and weighed. Dry stones were placed on marked paper and photographed, after which they were crushed, placed in chloroform or ethanol, dried and weighed again. The gallbladder was measured, weighed and fixed in buffered formalin $(100 \mathrm{ml} / 1)$ for histological examination. The gallbladder specimens were processed and embedded in wax in the conventional way, stained with $\mathrm{H}$ and $\mathrm{E}$ for gallbladder morphology, periodic acid Schiff for the staining of neutral mucins of the gallbladder mucosa, alcian blue and high iron diamine-alcian blue for the staining of both acidic and sulphated mucins, and periodic acid Schiff-alcian blue with and without deamination to show acidic mucins masked by linkage to protein. The appearance and intensity of the staining of acidic and sulphated mucins was graded as follows: (1) trace, (2) positive staining, (3) strongly positive and (4) strongly positive with the presence of sulphated mucins. Both bile and gallstone weight were compared with the intensity of staining of the acidic and sulphated mucins. 
Table 2. Weight of vervet monkeys (Cercopithecus aethiops) fed on either the casein or the soya-bean diets*

(Mean values with their standard errors)

\begin{tabular}{|c|c|c|c|c|c|c|}
\hline \multirow[b]{2}{*}{ Group } & \multirow[b]{2}{*}{ Protein } & \multirow[b]{2}{*}{ Sex } & \multicolumn{2}{|c|}{ Wt at commencement $(\mathrm{kg})$} & \multicolumn{2}{|c|}{$\mathrm{Wt}$ at termination $(\mathrm{kg})$} \\
\hline & & & Mean & SE & Mean & $\mathbf{S E}$ \\
\hline \multirow[t]{2}{*}{1} & Casein & $a$ & 5.84 & $0 \cdot 11$ & 5.69 & 0.19 \\
\hline & & $q$ & $3-23$ & $0 \cdot 14$ & $3 \cdot 11$ & $0 \cdot 20$ \\
\hline \multirow[t]{2}{*}{2} & Soya-bean & to & 5.29 & $0 \cdot 39$ & 5.51 & $0 \cdot 15$ \\
\hline & & $q$ & $3 \cdot 19$ & $0 \cdot 13$ & 3.40 & $0 \cdot 10$ \\
\hline
\end{tabular}

* For details of diets, see p. 258 and Table 1.

Plasma prepared from blood samples by centrifugation (4000 rev/min for $20 \mathrm{~min}$ ) was used for the assay of total plasma triglycerides, very-low-density-lipoprotein (VLDL)triglycerides, total cholesterol, high-density-lipoprotein (HDL)-cholesterol and VLDLcholesterol levels. Cholesterol and triglyceride concentrations were measured on the Gilford clinical chemistry system using enzymic assays from Böhringer-Mannheim and Gilford diagnostics respectively.

The analyses of bile for bile acid, phospholipid and cholesterol levels were carried out as follows : bile was diluted with isopropanol for the assay of cholesterol, and with methanol for the assay of total bile acids and phospholipids according to the method of Bolton et al. (1978). Portions of these extracts were evaporated to dryness and the phospholipids estimated by the procedure of Itaya \& Ui (1966) after perchloric acid digestion, the bile acids by the $3 \alpha$-hydroxysteroid dehydrogenase (EC 1.1.1.50) method of Bruusgaard et al. (1977) and biliary cholesterol by gas-liquid chomatography using a Varian model 3700 dual-flame-ionization detector gas-liquid chromatograph fitted with a $1.3 \mathrm{~m}, 3 \mathrm{~mm}$ i.d. column containing $3 \%$ SP-2250 on 100/200 Supelcoport. The column temperature was $270^{\circ}$, detector temperature $310^{\circ}$, injector temperature $290^{\circ}$ and the carrier-gas (nitrogen) flow-rate $30 \mathrm{ml} / \mathrm{min}$. The flow-rate of hydrogen was $30 \mathrm{ml} / \mathrm{min}$. The calculation of the lithogenic index was carried out according to the procedure of Metzger et al. (1972) and Thomas \& Hofman (1973).

\section{RESULTS}

During the experiment there was a non-significant increase in the mean weight in both groups at first, probably in response to the new dietary regimens. This effect was not maintained and the final weights were as indicated in Table 2. One female monkey from the casein-treated group developed diabetes and died in the 9 th month of the experiment and was thus excluded from final assessment.

In the present study all the twenty monkeys of both groups developed more or less advanced cholelithiasis. The gallstones varied in appearance from single spherical or sharpedged stones occupying up to $50 \%$ of the gallbladder volume to multiple small stones and crystals. All stones were dark brown or black, although some stones in the casein-treated group had a paler appearance. Gallstones from both groups were only partially soluble in chloroform or in ethanol, and were therefore considered to be pigment gallstones. The mean percentage of the stones dissolved in chloroform and ethanol in the casein dietary group was 2.71 (SD 1.58) and in the soya-bean dietary group, 1.93 (SD 1.55). 
Table 3. The effect of dietary casein and soya-bean protein* on the plasma lipid composition ( $\mathrm{mg} / \mathrm{l}$ ) in vervet monkeys (Cercopithecus aethiops)

(Mean values with their standard errors)

\begin{tabular}{|c|c|c|c|c|c|c|c|c|}
\hline & \multicolumn{4}{|c|}{ Casein } & \multicolumn{4}{|c|}{ Soya bean } \\
\hline & \multicolumn{2}{|c|}{ Baseline } & \multicolumn{2}{|c|}{ Termination } & \multicolumn{2}{|c|}{ Baseline } & \multicolumn{2}{|c|}{ Termination } \\
\hline & Mean & SE & Mean & $\mathrm{SE}$ & Mean & SE & Mean & $\mathbf{S E}$ \\
\hline Total serum triglycerides & 900 & 60 & 1960 & 110 & 940 & 60 & 2070 & 240 \\
\hline VLDL-triglycerides & 130 & 40 & 230 & 30 & 110 & 30 & 290 & 80 \\
\hline Total serum cholesterol & 1440 & 70 & 7020 & 660 & 1360 & 90 & 7920 & 730 \\
\hline VLDL-cholesterol & 30 & 10 & 390 & 70 & 50 & 10 & 480 & 10 \\
\hline HDL-cholesterol & 1030 & 40 & 350 & 30 & 990 & 60 & 400 & 40 \\
\hline
\end{tabular}

VLDL, very-low-density-lipoprotein; HDL, high-density-liproprotein.

* For details of diets, see p. 258 and Table 1.

Table 4. Effects of dietary casein and soya-bean protein* on gallstone formation and biliary constituents in vervet monkeys (Cercopithecus aethiops)

(Mean values with their standard errors)

\begin{tabular}{|c|c|c|c|c|}
\hline & \multicolumn{2}{|c|}{ Casein } & \multicolumn{2}{|c|}{ Soya-bean } \\
\hline & Mean & SE & Mean & SE \\
\hline Bile mass (g) & 2.8 & 1.0 & $2 \cdot 3$ & $0 \cdot 3$ \\
\hline Dry stone mass (mg) & $13 \cdot 3$ & $3 \cdot 2$ & 18.6 & $6 \cdot 3$ \\
\hline \multicolumn{5}{|l|}{ Absolute concentration $(\mathrm{mmol} / \mathrm{l})$} \\
\hline Bile acids & 306 & $12 \cdot 6$ & 275 & $16 \cdot 6$ \\
\hline Cholesterol & $10 \cdot 2$ & 0.9 & $8 \cdot 8$ & 0.6 \\
\hline Phospholipid & 50 & $3 \cdot 6$ & 43 & $3 \cdot 0$ \\
\hline \multicolumn{5}{|l|}{ Molar ratio } \\
\hline Bile acids & 0.836 & 0.007 & 0.838 & 0.009 \\
\hline Cholesterol & 0.028 & 0.002 & 0.028 & 0.003 \\
\hline Phospholipid & $0 \cdot 136$ & 0.008 & $0 \cdot 134$ & 0.008 \\
\hline Lithogenic index & 0.32 & 0.07 & $0 \cdot 31$ & 0.08 \\
\hline
\end{tabular}

* For details of diets, see p. 258 and Table 1.

The mean bile weight and dry stone weight in the casein-treated group were slightly different to those of the soya-bean-protein-treated group $(2.8 \mathrm{~g}, 13.3 \mathrm{mg}$ and $2.3 \mathrm{~g}, 18.6 \mathrm{mg}$ respectively) but those differences were not significant. The mean stone weight in the males was higher than that in the females but in neither group were the differences significant.

Gallstone weights were not significantly correlated to the individual plasma cholesterol levels, which were very high in all animals in both groups. No significant differences in total cholesterol, or triglyceride concentrations in serum or in any of the lipoprotein classes were found to be related to the source of the dietary protein (Table 3). Similarly no significant difference was found in the concentrations of the bile constituents (phospholipids, cholesterol and bile acids levels) in the two groups. The lithogenic index of the samples taken from the gallbladders of both groups never rose above 0.38 for the soya-bean-fed group or above $\mathbf{0 . 4 4}$ for the casein-fed group (Table 4). Histological examination of the livers of both groups showed in isolated cases that mild mononuclear cell infiltration had occurred in periportal areas. Intrahepatic bile ducts were free from any pathological 


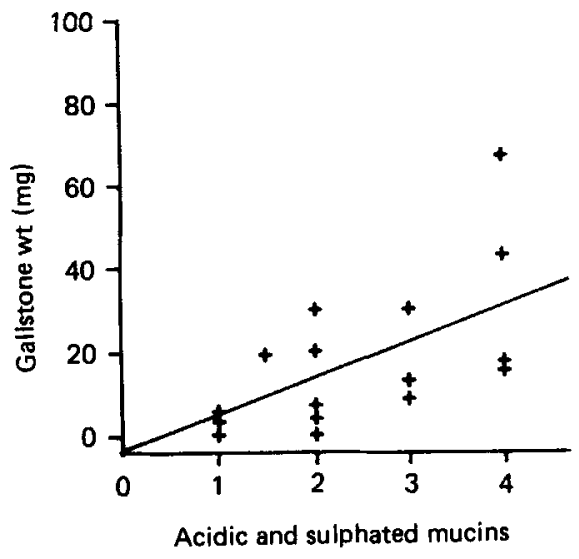

Fig. 1. Gallstone weight $v$. the acidic and sulphated mucins in vervet monkeys (Cercopithecus aethiops) given casein or soya-bean-protein diets $(r 0.62, P<0.01)$. Grading of the appearance and intensity of the staining of acidic and sulphated mucins: (1) trace, (2) positive staining, (3) strongly positive, (4) strongly positive with the presence of sulphated mucins. For details of methods used for the grading of the intensity and staining of the mucins, see p. 258.

changes. The gallbladder mucosa in both groups showed mostly mild but in some cases moderate atrophy. There were no histochemical differences in the gallbladder mucins found in the two groups of animals. Acidic and sulphated gallbladder mucins were correlated to gallstone weight $(r 0.62, P<0.01)$ (Fig. 1).

\section{DISCUSSION}

Human cholelithiasis is a multifactorial disease and therefore the finding or development of a spontaneous genetic model is unlikely. The two most popular animals in use today as models are both rodent species, the hamster and the prairie dog, in which cholesterol overload $(0 \cdot 1-1 \cdot 2 \%)$ is used as a basic method in developing cholesterol gallstones. Of the sub-human primates on long-term high-cholesterol diets, several species are known to be resistant to cholesterol gallstone formation, notably rhesus and African green (vervet) monkeys (Holzbach, 1984).

St Clair et al. (1980), in an experiment with twenty-three African green monkeys given $2.7 \mathrm{~g}$ cholesterol and $235 \mathrm{~g}$ fat $/ \mathrm{kg}$ over 20 months, showed cholesterol gallstones in only three monkeys. Our findings of pigment lithiasis in all twenty monkeys fed on $5 \mathrm{~g}$ cholesterol and $200 \mathrm{~g}$ butter $/ \mathrm{kg}$ diet suggest that vervet monkeys may be a very suitable animal model of cholelithiasis, since their much larger size offers distinct advantages over the small squirrel monkeys. Unlike squirrel monkeys, used in the classical experiments by Osuga \& Portman and their co-workers (Osuga \& Portman, 1971; Osuga et al. 1974) the vervet monkeys in our experiment developed pigment gallstones, with supersaturation of the bile by cholesterol not being evident. The molar concentrations of phospholipids, cholesterol and bile acids (Table 4) were very similar to those found in vervet monkeys fed on a prudent diet for 18 months, i.e. cholesterol 10.9 (SE 1.1), phospholipids 35.4 (SE 2.2) and bile acids 284.8 (SE 25.7) mmol/l with a lithogenic index of 0.42 (SE 0.04) (n 8). In a group of thirty monkeys fed on a stock diet a lithogenic index of 0.17 (SE 0.01) was found (M. J. Weight, unpublished results). Thus in the present experiment it is certain that we are not dealing with classical cholesterol gallstone formation in which a supersaturating concentration of cholesterol is a necessary condition. What is more likely is that the diets given caused an 
increased secretion of negatively-charged sulphomucins which participated in the formation of calcium carbonate or calcium bilirubinate stones. Both Maki et al. (1971) and Nagashima et al. (1974) have shown that sulphated glycoproteins from bile can act as a nucleating or precipitating agent for $\mathrm{CaCO}_{3}$. The increased secretion of gallbladder mucin has been shown to give rise to mixed or pigment stones (Smith \& LaMont, 1984) and also the development of an acid $\mathrm{pH}$ on the gallbladder surface has been implicated in calcium bilirubinate precipitation (Malet et al. 1986).

Not only is the role of diet in pigment-stone formation unknown, but in sharp contrast to the formation of cholesterol gallstones little is known about the composition of bile surrounding pigment stones (Soloway, 1977). Our results on bile composition appear to be in agreement with two reports which have characterized gallbladder bile from human patients with pigment stones. Both of these studies characterized the bile as having less cholesterol, but similar amounts of bile salts and phospholipids (Izumi, 1965; Trotman et al. 1974). Both these studies indicate that the abnormality leading to pigment lithiasis is not related to supersaturation of gallbladder and hepatic bile with cholesterol (Soloway et al. 1977).

The lack of a protective action of the soya-bean protein on cholelithiasis as shown in hamsters by Kritchevsky \& Klurfeld (1979) could be due to interspecies differences in lithogenesis and the type of gallstones formed. Our results also do not confirm the hypocholesterolaemic effect found by Terpstra et al. (1984) in rhesus monkeys, or by Mahfouz-Cercone et al. (1984) in hamsters, of soya-bean protein when compared with casein. St Clair et al. (1980) have also suggested higher plasma HDL-cholesterol, plasma triglyceride concentration and bile cholesterol saturations in female vervet monkeys fed on a high-cholesterol diet. In the present experiment we observed similar values for those variables in both male and female monkeys. Further experiments with cholelithiasis will clarify species differences and irregular responses to unnaturally high-cholesterol and highfat diets.

The authors would like to thank Mr Jürgen Seier for assistance with the animals and diets, and $\mathrm{Mr}$ Colin Woodroof and $\mathrm{Mr}$ Thinus van Wyk for technical assistance. This work was supported in part by a research career award (HL-00734) and a research grant (HL-03299) from the National Institutes of Health, USA. They are also indebted to the Ralston Purina Company, St Louis, Missouri, for providing the soya-bean-protein isolate.

\section{REFERENCES}

Bennion, L. J. \& Grundy, S. N. (1978). New England Journal of Medicine 299, 1161-1167.

Bolton, C. H., Low-Beer, T. S., Pomare, E. W., Wicks, A. C. B., Yeates, J. \& Heaton, K. W. (1978). Clinica Chimica Acta 83, 177-181.

Bruusgaard, A., Sorensen, H., Gilhuus-Moe, C. C. \& Skalhegg, B. A. (1977). Clinica Chimica Acta 77, 387395.

Dreyer, J. J. \& Du Bruyn, D. B. (1968). South African Medical Journal 42, 600-604.

Holzbach, R. T. (1984). Hepatology 4, 1915-1985.

Itaya, K. \& Ui, M. (1966). Clinica Chimica Acta 14, 361-366.

Izumi, K. (1965). Fukuoka Acta Medica 56, 488-523.

Kameda, H. (1964). Gastroenterology 46, 109-114.

Kritchevsky, D. \& Klurfeld, D. (1979). American Journal of Clinical Nutrition 32, 2174-2176.

Kritchevsky, D. \& Klurfeld, D. (1983). American Journal of Clinical Nutrition 37, 802-804.

La Morte, W. W., Matolo, N. M., Birkett, D. H. \& Williams, L. F. Jr (1981). Surgical Clinics of North America 61, $765-774$.

Mahfouz-Cercone, S., Johnson, J. E. \& Liepa, G. J. (1984). Lipids 19, 5-10.

Maki, T., Matsushiro, T. \& Suzuki, N. (1971). Surgery, Gynecology and Obstetrics 132, 846-851.

Malet, P. F., Deng, S. Q., Locke, C. L. \& Soloway, R. D. (1986). Gastroenterology 90, 1744-1794.

Metzger, A. L., Heymsfield, S. \& Grundy, S. M. (1972). Gastroenterology 62, 499-501. 
Nagashima, H., Suzuki, N. \& Yosizawa, Z. (1974). Tohoku Journal of Experimental Medicine 113, $159-168$.

Osuga, T. \& Portman, O. W. (1971). Proceedings of the Society of Experimental Biology and Medicine 136, 722726.

Osuga, T., Portman, O. W., Mitamura, K. \& Alexander, M. (1974). Laboratory Investigation 30, 486-493.

Smith, B. F. \& LaMont, J. J. (1984). Hospital Practice 93-104.

Soloway, R. D., Trotman, B. W. \& Ostrow, J. D. (1977). Gastroenterology 72, 167-182.

St Clair, R. W., Henderson, G. R., Heaster, V., Vagner, W. D., Bond, M. G. \& McMahan, M. R. (1980). Atherosclerosis 37, 103-121.

Sullivan, M. A., Duffy, A., Dimarco, N. \& Liepa, G. (1985). Lipids 20, 1-6.

Terpstra, A. H. M., West, C. E., Fennis, J. C. M., Schouten, J. A. \& Van der Veen, E. A. (1984). American Journal of Clinical Nutrition 39, 1-7.

Thomas, P. J. \& Hofman, A. F. (1973). Gastraenterology 65, 698-700.

Trotman, B. W., Ostrow, J. D. \& Soloway, R. D. (1974). American Journal of Digestive Diseases 19, 585-590.

Yagi, T. (1960). Tohoku Journal of Experimental Medicine 72, 117-130. 